\title{
Obstacle course for our toys
}

\author{
Jimena Ferreyros ${ }^{1}$
}

${ }^{1}$ Affiliation not available

May 24, 2021

This lesson is managed for kids in nursery (3-4 years old), so they can learn through playing about STEAM. I'm going to concentrate in the area of construction and recycling because in my opinion, kids can learn a lot using those things.

Children in early childhood can develop a love for STEM and a feeling of efficacy for their own abilities that can support their learning. Using their own toys we can capture the child's love for science, math, engineering, arts and technology. Also encouraging them to explorate and to be curious through insightful questions and celebrating secces as well as failure, so they can go on and on investigating.

\section{Goal:}

Create obstacles of all type to a course that the kids have to build in their neighborhood, in orther to learn about how important it is to mantaine clean the streets, the green parts and the enviroment.

\section{Materials:}

1. Toys for construction (legos, blocks, among others).

2. Recycled materials for construction (boxes, toilet paper tubes, paperboard, among others).

3. Paper, colored pencils, tape and other tools to decorate the course and neighborhood.

4. Toys to play after you finish with your construction (vehicles, persons, animals and plants). 


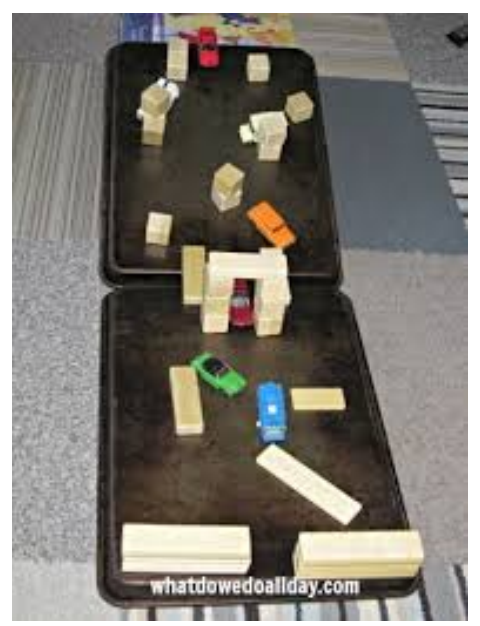

Figure 1: Different materials the kids will need.

\section{Space:}

1. "Construction area": Big space in the classroom so the kids can build in peace. We are going to need space for all the materials and also tapers pointing where is each thing with a picture, so the kids can clean everything after using it.

2. A quiet spaceso the kids can concentrate while they are drawing their designs, building and looking for the pieces.

3. Also it is a place so that the kids can work in teams and learn what team work means.

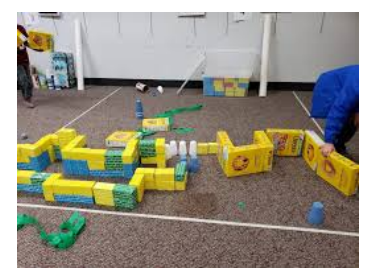

Figure 2: A big space for all the materials and children to move around.

\section{Questions to make the kids:}

1. How many times did you need to draw your construction before you began building?

2. Can you make something where your toys have to go under, over and around? Show me.

3. With how many legos, blocks, or boxes did you build that tower and road?

4. Which building is taller than the other?

5. How more triangles than rectangles did you use to build that house?

6. How many obstacles are there and why do you think are this obstacles there? 
7. What can we do to improve traffic in your course?

8. Do all this obstacles help the enviroment? What do you think?

9. What can we do to make a better course for you, your family and the neirborhood?

10. Would you make a machine maybe to clean your neighborhood? or what could you do?

11. Can you continue this at home and send us a video of your obstacle course?

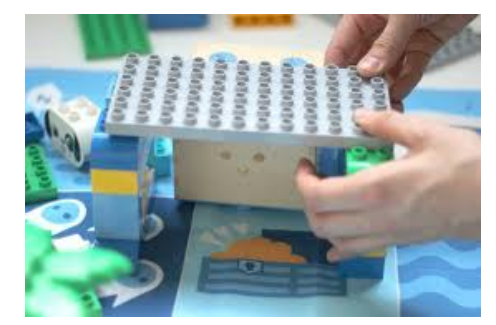

Figure 3: Types of construction.

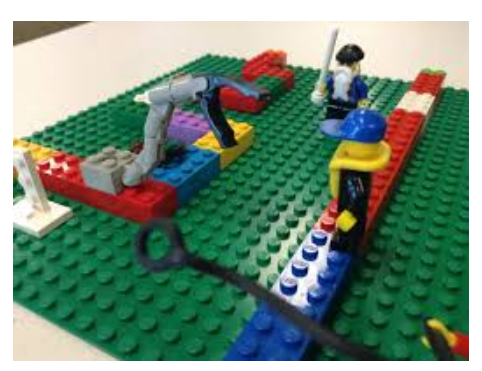

Figure 4: Types of construction.

\section{Conclusion:}

I really hope that with this lesson the children learn a lot about the diferent STEM areas, about their neighborhood, the enviroment, how to protect and clean the streets, how to work in teams with each other, know how to count using the construction materials, learn about recycling and the fun part of it and all of this by playing at school and also at their homes.

It's been a wonderfull jurney for me to read and see all of this information, I'm really motivated in using all of this in Perú and making a great change in education. 